\title{
ETHOS MERCANTIL CAPITALISTA E OS DESAFIOS À AUTORREALIZAÇÃO HUMANA PELO TRABALHO
}

\author{
MERCANTIL CAPITALIST ETHOS AND THE CHALLENGES TO HUMAN SELF-EVALUATION BY \\ WORK
}

Rutinéa Alves Ferreira*

\begin{abstract}
RESUMO
O artigo apresenta, de forma sumária, a problemática da autorrealização humana na sociabilidade fetichista da economia do capital, sublinhando o fato de que, no interior de suas relações, o sujeito que trabalha se autoproduz e se reproduz como estranho à sua própria humanidade. Nesse sentido, a abordagem expõe as mediações fundamentais que constituem historicamente os processos de (auto)alienação e reificação do ser que trabalha, instaurando um ethos que nega a efetivação das potencialidades humanas no processo e no resultado da atividade produtiva. Tematiza, pois - a partir do pensamento de Marx e de alguns de seus seguidores - o caráter paradoxal dos desafios inerentes à determinação da práxis histórica marcada, moderna e contemporaneamente, pelo recrudescimento dos obstáculos à afirmação do homem como ser livre e criativo.

PALAVRAS-CHAVE: Trabalho. Autorrealização Humana. Estranhamento. Fetichismo do Capital. Reificação.
\end{abstract}

\section{ABSTRACT}

The article summarizes the problematic of human self-realization in the fetishist sociability of the economy of capital, underlining the fact that, within their relations, the subject who works produces himself and reproduces himself as strange to his own humanity. In this sense, the approach exposes the fundamental mediations that historically constitute the processes of (self)alienation and reification of the being who works, establishing an ethos that denies the effectiveness of human potentialities in the process and the result of productive activity. Approaches, from the thought of Marx and some of his followers, the paradoxical character of the challenges inherent in the determination of historical praxis marked, in modern and contemporary times, by the recrudescence of obstacles to the affirmation of the man as a free and creative being.

KEYWORDS: Work. Human Self-Realization. Strangement. Capital Fetishism. Reification.

\footnotetext{
* Mestre em Filosofia pela Faculdade Jesuíta de Filosofia e Teologia/FAJE, especialista em Filosofia e Bacharel em Serviço Social pela PUC-Minas. E-mail: rutinhaalves@ hotmail.com.
} 


\section{INTRODUÇÃO}

As problematizações que aqui se apresentam ancoram-se fundamentalmente na concepção de trabalho desvelada por Marx em sua crítica da sociabilidade capitalista. Porém, de início, destaca-se, mais particularmente, o fato de ser a partir dessa crítica que o filósofo alemão depreende a natureza geral da atividade produtiva, isto é, aquela desvinculada de toda forma concreta de produção contraída em relações sociais determinadas. Desse modo, na tentativa de ressaltar, em face de tal natureza, as inversões inerentes à produção capitalista, parte-se dos elementos centrais que consubstanciam o trabalho como a categoria constitutiva do homem na qualidade de ser historicamente autofundado e, por isso, autorrealizado.

No transcurso da abordagem, apresentam-se os desdobramentos centrais das mediações que constituem as formas-fetiche das relações sociais de produção. O fetiche do capital aparece como o ponto culminante do processo de conversão do trabalho em um processo por meio do qual o homem se desumaniza quando produz suas condições materiais de existência.

A reprodução do estranhamento e da reificação ${ }^{1}$ expõe-se como característica decisiva da economia do capital. Seus efeitos dramáticos, negadores da humanidade outrora conquistada pelo homem no seu ato produtivo, tendem a conduzir ao esquecimento da centralidade ontológica do trabalho. Porém, mesmo defronte às mediações históricas configuradoras do ethos atual, ressalta-se a importância de reconhecer o ser que produz, não como um mero trabalhador, despojador de sua força produtiva, mas como um ser dotado, essencialmente, de liberdade e criatividade a serem atualizadas na sua relação com o seu fazer, consigo e com o outro.

\section{TRABALHO E AUTORREALIZAÇÃO HUMANA}

Em A ideologia alemã (1998), Marx explicita, juntamente com Engels, a noção de trabalho também presente nos Manuscritos econômico-filosóficos (2004a), onde, no entanto, ela aparece mais desenvolvida e lançando luzes sobre os aspectos fundamentais da natureza

\footnotetext{
${ }^{1}$ Os conceitos de estranhamento e reificação estão relacionados à propriedade privada dos meios de produção, da qual decorre o distanciamento do trabalhador do produto de seu trabalho, em cujo processo ele já não pode mais manifestar-se como vontade livre e criativa. Todavia, mais especificamente, a reificação associa-se ao fetiche da mercadoria - produto histórico da apropriação privada dos meios de produção. A reificação, portanto, radicaliza o estranhamento pois o ser que trabalha é afirmado como objeto do processo de produção, submetido à personagem central da sociabilidade mercantil, qual seja, a mercadoria (LUKÁCS (2003).
} 
humana. Guardadas as peculiaridades de cada obra, de saída o trabalho é definido, em ambas, como o pressuposto da existência histórica do homem, dado que o ato produtivo consiste na mediação primordial da relação entre o ser que trabalha e a natureza, com vistas à satisfação das necessidades humanas vitais.

O primeiro fato histórico é, portanto, a produção dos meios que permitem satisfazer essas necessidades, produção da própria vida material; e isso mesmo constitui um fato histórico, uma condição fundamental de toda história que se deve, ainda hoje como há milhares de anos, preencher dia a dia, hora a hora, simplesmente para manter os homens com vida. (MARX; ENGELS, 1998, p. 21).

Além de ser o substrato da manutenção material da vida, o trabalho é, em sua forma geral - como categoria ontológica -, a atividade por meio da qual o homem realiza suas potências criativas na natureza, afirmando a própria natureza humana. Isso significa que o ato de produzir é constitutivo do homem como um ser essencialmente distinto de tudo o que existe no mundo físico. No entanto, a diferenciação qualitativa que se manifesta em cada ato de trabalho não resulta em um confronto antitético entre o propriamente humano e o natural, visto ser impossível ao ser que trabalha negar o seu vínculo necessário com a natureza.

Tal distinção se estabelece no próprio interior da relação entre um e outra homem e natureza -, no curso da criação produtiva como atividade vital e cuja finalidade é sempre antecipada na consciência humana. Na ausência dessa instância, a consciência, qualquer ato de trabalho não passaria de mero esforço instintivo e em nada se distanciaria qualitativamente das tarefas de uma aranha ou de uma abelha - respectivamente análogas aos ofícios de um tecelão e de um arquiteto. A atividade da consciência consiste, portanto, naquele elemento especificamente humano que faz do trabalho uma dimensão essencial e uma tarefa exclusiva do homem.

Diferentemente do modo como a consciência ativa é definida no âmbito do idealismo alemão ${ }^{2}$ - em que o homem e sua atividade aparecem como predicados do Espírito auto-objetivado historicamente -, no pensamento de Marx ela é referida ao próprio sujeito que age concretamente e, ao fazê-lo, produz sua própria história. Assim entendida, a consciência

\footnotetext{
2 Embora Marx se inspire nas categorias fundamentais do pensamento de Hegel, como a dialética e a história, ele realiza as inversões necessárias para instaurar e defender as bases de seu materialismo histórico. Nesse sentido, recusa, de modo vigoroso, a concepção de história como manifestação do Espírito Absoluto, isto é, da consciência pura como sujeito da história independente dos sujeitos reais e que se autorrealiza num movimento dialético de autodesdobramento do pensamento na realidade concreta. Os argumentos de Max em relação às teses hegelianas aparecem desenvolvidos na obra A ideologia alemã (1998) e nos Manuscritos econômicofilosóficos (2004a). Um balanço crítico do distanciamento entre ambos os pensadores é encontrado no capítulo intitulado Marxismo e ontologia da obra Ontologia e história de Henrique Cláudio de Lima Vaz (2012).
} 
situa-se no cerne da constituição do trabalho como pertencente exclusivamente ao homem; ao mesmo tempo, porém, ela se desenvolve mediante as determinações históricas da produção material da vida. É nesse sentido que Marx chama a atenção para a dimensão real da consciência humana, ultrapassando o tratamento especulativo dedicado a ela em decorrência de sua apreensão como instância pura, abstrata. Contrariamente, ele defende que toda atividade somente é transformadora da realidade como autoatividade prática humana e não como autoatividade de uma consciência não situada ${ }^{3}$.

Uma consciência situada volta-se reflexivamente para os mundos material e relacional, conhecendo-os de modo efetivo e atuando neles com a finalidade de torná-los outros. É dessa capacidade reflexiva que decorre a "superioridade da arquitetura humana à admirável precisão de uma colmeia”. Tal argumento clarifica a distinção, anteriormente mencionada, entre a aranha e o tecelão e a abelha e o arquiteto, dado que um animal não pode ser produtor "porque ele não conhece reflexivamente" (GUEDES, 2014, p. 34, grifos do autor).

Inserido na mesma moldura temática, Lukács ${ }^{4}$ (1979) coloca em relevo o fato de a consciência reflexiva - antecipadora da finalidade de sua própria atividade na relação com o mundo objetivo - dotar o homem da específica capacidade de escolher os meios para a realização do trabalho. Efetivamente, é exclusiva dele a capacidade de submeter as matériasprimas à sua vontade, razoando as combinações adequadas em face das determinações da natureza para, por fim, conferir existência material ao produto ideado. Ademais, somente o homem, capaz de captar o mundo em suas múltiplas perspectivas, pode criar para si novas necessidades e avançar na produção de respostas que as satisfaçam. Ao fazê-lo, ele exterioriza-se no mundo como um ser que se autodetermina, ou seja, como aquele que toma a decisão de responder às suas necessidades naturais e àquelas por ele criadas; que responde a elas de modo consciente e de acordo com a sua vontade.

\footnotetext{
${ }^{3}$ Também na obra A ideologia alemã, juntamente com Engels, Marx elabora sua crítica ao materialismo de Feuerbach, apesar de suas contribuições opositivas ao idealismo alemão. Segundo Feuerbach, os objetos sensíveis são efetivamente distintos dos objetos do pensamento. No entanto, para ele, a relação entre a consciência e a realidade material restringe-se a uma atividade meramente contemplativa, o que significa uma relação de externalidade entre ambas. Para Marx e Engels (1998, p. 99, grifos dos autores), este é o maior defeito do materialismo feuerbachiano em que está implicada a sua concepção de consciência, da qual se depreende que "o objeto, a realidade, o mundo sensível só são apreendidos sob a forma de objeto ou de intuição, mas não como atividade humana sensível, enquanto práxis, de maneira não subjetiva".

${ }^{4}$ Apesar de desenvolver as categoriais fundamentais do pensamento de Marx, explicitando a perspectiva ontológica inerente a suas teses, as extrapolações interpretativas de Lukács são tomadas como objetos da crítica de outros seguidores de Marx. Um bom exemplo dessa crítica é encontrado na obra Para além do capital de István Mészáros (2011).
} 
Nos termos lukacsianos, a exteriorização constitui-se como um momento fundamental do trabalho no qual a realidade posta, criada como nova objetividade, retorna ao seu criador não como algo autônomo, estranho a ele, mas como algo que expressa a sua própria humanidade. No decorrer do processo de reprodução social, o homem se autorrealiza como ser de liberdade; isto é, como portador de um atributo somente dele, porque, em sendo também um ser natural, é exclusiva dele a escolha dos modos de expressar suas potencialidades na própria esfera da necessidade. Por isso, ao mesmo tempo em que a necessidade o limita e se lhe impõe, ela é captada pelo homem como estímulo, como pergunta carente de resposta, a qual ele assume reflexivamente, decidido a respondê-la para, então, estabelecer uma nova relação com a natureza. Essa nova relação, ao retornar ao sujeito do trabalho, dá-lhe evidências de que estar frente ao mundo natural transformado por sua própria ação significa estar frente a si mesmo.

[Assim] emerge o trabalho como "mediador de liberdade": por ele o homem exterioriza-se nas coisas, mas também por ele o homem se conquista, pois, pela ação sobre a natureza, ele se liberta de seu jugo. Ao invés de ser dominado pela natureza, o homem, através de sua práxis transformadora, se faz senhor da natureza e por esse senhorio se conquista como ser livre. (OLIVEIRA, 1993, p. 252-253).

Em síntese, ainda que não possa emancipar-se estritamente das determinações naturais, é pelo trabalho que o homem salta da condição meramente biológica para se autorrealizar como ser que produz sua própria condição de existência e, avante disso, adentra em um continuum de desenvolvimento das potencialidades inerentes ao seu ser. A transformação de si, a partir desse salto qualitativo, ocorre em simultâneo com a transformação do mundo natural. Isso se dá, inevitavelmente, porque o ser que trabalha faz transparecer suas faculdades através de uma relação de autoexpressividade do humano no mundo objetal.

Marx define essa relação como práxis humanizadora da natureza. Isso, por tudo o que já foi exposto até aqui e sumariado no fato de que é no mundo natural que o homem manifesta suas capacidades e efetiva-se como fim de sua própria atividade. Em outras palavras, ao imprimir no processo de produção e no produto de seu trabalho sua inteligência e sua vontade, o homem que trabalha realiza a sua essência, afirmando-se e sendo afirmado como automediador de sua própria humanidade e da humanização do mundo natural. Enquanto “o animal é um ser imediato, o homem é um ser da mediação". Por isso, é tarefa sua "tornar humano tanto a si mesmo como aos objetos que o reproduzem materialmente, [já que] 
nem a natureza objetiva nem a natureza subjetiva [lhe] são imediatamente adequadas" (OLIVEIRA, 1993, p. 205).

Igualmente inspirado no pensamento marxiano, Vázquez (2007) também argumenta que a automediação implicada nos processos de trabalho expressa o poder do homem objetivar-se, pois ele objetiva suas próprias finalidades e a si mesmo como o fim de toda atividade produtiva. Nesses termos, a objetivação é desvelada como atividade autorrealizadora e, portanto, radicalmente distinta daquela vinculada, em sua forma geral, à ideia de alienação constitutiva da dialética hegeliana.

Daí que, ao invés de ser admitida como perda de si em algo que lhe é externo, a objetivação é afirmada como necessária, essencial, constitutiva do homem como ser autoproduzido e que se reproduz como tal no mundo humano. É por meio dela que a essência humana se consubstancia ao longo do desenvolvimento do ser que trabalha. E é assim que se certificam as suas dimensões prática e histórica, já que ela nunca é dada a priori, mas, ao contrário, realizada efetivamente no curso da existência, cujo pressuposto - uma vez mais - é a (re)produção material da vida. Logo,

se em vez de partir da essência do homem [como algo abstrato], parte-se dos indivíduos reais, de suas ações práticas e de suas condições materiais de existência; se os homens não são algo à parte do que manifestam, isto é, de sua vida real e de sua história, já não cabe falar de uma essência humana divorciada da existência. (VÁZQUEZ, 2007, p. 405).

Diante da impossibilidade de se refutar que a realização do homem se faz enquanto ele constrói a própria existência material, há que se destacar também que a reprodução de tal processo implica, fundamentalmente, uma dimensão social. Quando Marx afirma ser o homem o produto de seu próprio trabalho, ele não se refere ao indivíduo relacionado apenas à atividade que realiza, já que o trabalho é, em si, uma atividade social. A prova cabal disso transparece a todo tempo na inevitável confrontação entre cada indivíduo e a realidade humanamente construída. Esta, mesmo contendo produtos cuja autoria seja ignorada, leva todos a tomarem consciência da condição comum de seres genéricos; isto é, de que eles pertencem a uma espécie cuja essência não coincide de modo direto com cada individualidade.

Precisamente por isso, na elaboração do mundo objetivo [é que] o homem se confirma, em primeiro lugar e objetivamente, como ser genérico. Esta produção é sua vida genérica operativa. Através dela a natureza aparece como sua obra e sua efetividade (Wirklichkeit). O objeto do trabalho é, portanto, a objetivação da vida 
genérica do homem: quando o homem se duplica não apenas na consciência, intelectual[mente], mas operativa[mente], efetiva[mente], contemplando-se, a si mesmo num mundo criado por ele. (MARX, 2004, p. 85, grifos do autor).

Tal como ocorre com a consciência criativa, a consciência de ser um ser genérico nunca se identifica com uma consciência abstrata, pois ela também se realiza nas relações reais entre os sujeitos, quando eles se relacionam com o mundo. Em outras palavras, "assim como a consciência especificamente humana só pode nascer em ligação e como efeito da atividade social dos homens [...], também a consciência de pertencer ao gênero se desenvolve a partir da convivência e da cooperação concreta entre eles" (LUKÁCS, 1979, p. 145). Por constituir-se apenas nesse processo é que ela possibilita a cada um duplicar-se como um ser da natureza e, ao mesmo tempo, como um ser social; como um indivíduo particular, mas essencialmente idêntico aos demais de sua espécie.

A sociabilidade é, então, a forma geral de vida na qual os homens se autorrealizam a partir do trabalho; por isso, ela é desvelada como mais um atributo essencial da natureza humana. No curso de seu desenvolvimento, constitui-se um processo de valoração que implica tanto a relação sujeito-objeto quanto a relação sujeito-sujeito. Para o sujeito, o trabalho e seus produtos assumem imediatamente a forma de valor de uso, diretamente relacionada às suas necessidades de reproduzir-se socialmente. Entre os sujeitos, no âmbito das relações permeadas pelas atividades produtivas, a exigência por um planejamento voltado ao alcance de determinadas finalidades instaura a base para o desenvolvimento de um sistema normativo. Tal sistema é configurado à luz de um ideal regulativo, um dever-ser individual e coletivo que se irradia, porém, para além da esfera da produção.

Desse modo, as relações de trabalho definem-se como instâncias fundamentais constitutivas do ethos, ou seja, do modo de vida dos indivíduos frente e junto aos outros. De acordo com Marx, todo modo de existência humana se edifica sobre e se expressa nessa esfera relacional denominada esfera econômica, onde a reprodução material da vida se faz incessantemente. É a partir, pois, da economia, entremeada por mediações objetivas e, ao mesmo tempo, por aquelas propriamente humanas, que é construído um modo geral de existir, também especificamente humano. Isso significa dizer que

a produção da vida material é, em primeira aproximação, o lugar do estritamente econômico em Marx. [Mas], por outro lado, toda economia é sempre um modo de essa produção se realizar, o que já implica uma determinidade da vida material pela intervenção criativa, pela atividade do sujeito humano. Constitui uma suprassunção da realidade sensível que revela no modo de produzir já uma conformação da vida propriamente humana. (GUEDES, 2014, p. 251, grifos do autor). 
Com esse conceito fica ainda melhor justificada a depreensão do trabalho como protoforma, isto é, como modelo de toda a vida social. Porém, a análise de suas questões fundamentais não implica o esquecimento da dimensão dialética da produção que, de modo inevitável, também é mediada por relações sociais historicamente determinadas.

De fato, a especificidade histórica das formas determinadas de mediação tem uma importância seminal na medida em que os indivíduos, por meio dos agrupamentos intermediários historicamente determinados e seus equivalentes institucionais, articulam-se respectivamente em um todo social mais ou menos densamente entrelaçado. É precisamente a especificidade mediadora inevitável das inter-relações reprodutivas dos indivíduos que acaba por definir, pela determinação mais ou menos direta das condições operacionais prevalecentes de produção [...], o caráter fundamental dos vários modos de intercurso social, historicamente contrastantes. (MÉSZÁROS, 2011, p. 880).

Com efeito, o desenvolvimento da existência material e cultural dos indivíduos revela formas particulares contraídas ao longo do percurso histórico da reprodução humana. Essas formas variam de acordo com as mediações constitutivas das relações de produção em cada período histórico, contrastando em menor ou maior grau com a forma geral do trabalho.

\section{A FETICHIZAÇÃO DAS RELAÇÕES SOCIAIS DE PRODUÇÃO}

No campo de determinidades históricas das relações produtivas, Marx toma como objeto central de sua crítica a economia capitalista, atento ao fato de ser ela o resultado evolutivo das formas anteriores de realização do trabalho. Não obstante todas elas conterem problemáticas inerentes ao seu modo de ser, Marx afirma que, tal como as formas que lhe antecedem, a sociabilidade capitalista é legítima e justificável, pois, além de se realizar como um desdobramento do processo socio-histórico, ela é quotidianamente reproduzida nas relações sociais dos indivíduos. E se é destinada à economia do capital uma crítica mais contundente, isso é porque, ao passo em que se reproduz, ela radicaliza a sua natureza opositiva à autorrealização do homem pelo trabalho. Inegavelmente, a sociabilidade capitalista é a que contrasta de modo mais drástico com a natureza geral do trabalho.

Antes de imergir-se na crítica marxiana do ethos em questão, importa ressaltar que qualquer sociabilidade opositiva à autorrealização humana tem dois pressupostos fundamentais: a divisão do trabalho e a propriedade privada. Ambas resultaram do desenvolvimento das forças produtivas no transcurso dos tempos e modificaram, 
substancialmente, a relação do homem que trabalha com todas as dimensões da vida. Vale sublinhar também a existência de uma relação ineludível entre tais pressupostos, visto que a propriedade privada tem sua origem na divisão do trabalho, mais especificamente no seu desdobramento em produção de excedentes apropriados por aqueles que não produzem. Marx afirma que, uma vez originada, a propriedade privada se impõe como uma mediação que imprime ao processo de trabalho uma nova concepção de exteriorização estritamente distinta daquela pertencente ao trabalho na sua forma geral. Isso porque a ela corresponde "a livre disposição da força de trabalho de outrem” (MARX; ENGELS, 1998, p. 27).

Sob a mediação da propriedade privada, independentemente do período histórico, o trabalho se torna externo ao homem. Converte-se em algo que não lhe pertence, nem como processo e menos ainda como resultado. Modificam-se, efetivamente, a relação do homem consigo mesmo, como trabalhador não-proprietário, e a sua relação com o proprietário nãotrabalhador. Desse modo,

se ele se relaciona [...] com o produto do seu trabalho, com o seu trabalho objetivado, enquanto objeto estranho, hostil, poderoso, independente dele, então se relaciona com ele de forma tal que um outro homem estranho (fremd), inimigo, poderoso, independente dele, é o senhor desse objeto. Se se relaciona com a sua própria atividade como uma [atividade] não livre, então ele se relaciona com ela como a atividade a serviço de, sob o domínio, a violência e o jugo de um outro. homem (MARX, 2004a, p.87).

A divisão do trabalho ${ }^{5}$, por sua vez, muito embora tenha criado as bases para a propriedade privada, não possui uma negatividade que lhe seja essencialmente constitutiva. Ao contrário, ela inaugurou as formas organizadas de produção, possibilitando a diminuição do tempo necessário de trabalho e, por conseguinte, a diversificação de produtos e a instauração de um sistema de trocas cada vez mais ampliado. Mas, apesar disso, Marx enfatiza o caráter negativo da especialização na economia capitalista, em face da parcialização radical das tarefas produtivas.

Em direção contrária, Adam $\operatorname{Smith}^{6}$ (1983, p. 75) defende que a divisão do trabalho é derivada de uma "propensão existente na natureza humana”, a saber, "a propensão

\footnotetext{
${ }^{5}$ Uma análise detalhada da divisão do trabalho é apresentada na quarta parte de $O$ capital (MARX, 2004b). No capítulo XII, o autor analisa as implicações da divisão do trabalho na sociedade e, especialmente, os desdobramentos de sua culminância na divisão do trabalho na manufatura.

${ }^{6}$ Na obra a Riqueza das nações, Adam Smith (1983), expoente da Economia Política Clássica, explicita a articulação existente entre a divisão do trabalho, a natureza humana e o desenvolvimento da sociedade. No "livro I" ele privilegia os aspectos considerados vantajosos na diversificação das atividades de trabalho pela
} 
a intercambiar ou trocar uma coisa pela outra". Assim considerada, ela seria a forma da autorrealização humana, ao mesmo tempo em que consiste na causa da profusão da riqueza material, já que amplia as relações comerciais como a base de toda sociedade civilizada. Ademais, de acordo com a tese smithiana, a especialização produtiva cumpre um importante papel integrador ao passo que exige a articulação dos esforços dos produtores, bem como dos proprietários individuais dos meios de produção. Voluntariamente ou não, eles precisam manter uma relação de interdependência em função exatamente da parcialização das atividades de trabalho. Por essas questões, uma sociedade é considerada tanto mais rica material e socialmente quanto mais avançada é a especialização do trabalho.

Marx contra-argumenta, afirmando que a simplificação do trabalho empobrece o espírito criativo, inventivo, do trabalhador. A compreensão de si por esse sujeito, bem como a compreensão de seu mundo, também se empobrece, pois o seu modo de ser, de existir material e socialmente tem sempre como base a sua relação com o trabalho, ou seja, com a reprodução social da vida. Do mesmo modo, há o empobrecimento dos vínculos sociais pois, ao se consagrar a relação de troca como o pressuposto fundamental de uma sociedade evoluída, cada sujeito, como portador daquilo de que o outro necessita, passa a ser tratado como mero meio para a satisfação de carências alheias. Para Marx, o autointeresse defendido por Smith como o motivo natural das relações de troca - não se converte na satisfação de interesses genuinamente coletivos e, por isso, a sociedade comercial, civilizada, rica materialmente, não coincide com uma sociedade autorrealizada humanamente. O próprio Smith admite mais tarde que "o motivo daquele que troca não é a humanidade, mas sim o egoísmo" (MARX, 2004a, p. 155, grifos do autor).

Portanto, enquanto Smith abstrai-se das formas determinadas de trabalho para privilegiar o fato de que este se constitui como originário e reprodutor de riqueza, Marx dirige sua crítica às consequências de sua modernização para a liberdade e a autocriação humanas. Toda a crítica marxiana é construída em torno da forma fetiche incorporada pela sociabilidade mercantil moderna; forma essa responsável pelo surgimento do dinheiro e, adiante, do capital, a partir do que o fetichismo se reproduz em toda a sua radicalidade.

O principal esforço da crítica elaborada por Marx é o de desnaturalizar o modo capitalista de produção, cujas categorias gerais, segundo os economistas políticos, valeriam

simplificação das operações produtivas. Apesar disso, ele demonstra não ser indiferente aos efeitos sombrios da especialização do trabalho, abordando-os no "livro I" de sua obra. 
para todos os tipos de sociedade, em qualquer época, desconsiderando as mediações presentes nas formas historicamente determinadas de trabalho. Marx desvela exatamente a complexidade e as contradições específicas da economia burguesa e como ela foi consolidando um ethos contrário à autoexpressividade humana, na sua criatividade e liberdade. Dito de outro modo, o filósofo alemão explicita os elementos a partir dos quais, não obstante abrigue a forma mais evoluída de produção, "a sociedade burguesa [revela ser] apenas uma forma opositiva do desenvolvimento" (GUEDES, 2014, p. 50).

Esse caráter paradoxal da sociabilidade mercantil capitalista é marcado pelo fetiche da mercadoria que se desdobrou no fetiche do dinheiro e acabou por converter-se em capital, também fetichizado e fetichizante. Já no início de tal processo as relações entre os seres humanos assumem uma forma invertida em que

\footnotetext{
o caráter social do trabalho manifesta-se [...] como caráter exterior objetivo de seus produtos, como se fossem as propriedades sociais deles. O valor é a forma pela qual o trabalho social se representa na economia mercantil, generalizando-se como conteúdo abstrato de uma expressão autonomizada em uma figura objetiva externa, que se afirma progressivamente como sujeito de si mesmo. (GUEDES, 2014, p. 123, grifos do autor).
}

Antes mesmo da instauração da economia do capital, há a inversão do sujeito das relações sociais. A mercadoria, com sua forma abstrata, a forma-valor, passa a ser o sujeito, enquanto os homens que a produzem aparecem como coisas, como os meios pelos quais ela se relaciona com outras mercadorias, isto é, se troca. O valor de uso dos produtos, a sua identidade concreta, cujo fim é suprir as carências humanas, é subsumido pelo valor de troca que dá materialidade à forma-valor. Eis a forma geral de toda sociabilidade mercantil em que a mercadoria consiste, ao mesmo tempo, “em algo perceptível e impalpável”, uma vez que aparece simplesmente como coisa, embora seja efetivamente uma relação social que permanece oculta na forma pela qual ela se apresenta (MARX, 2004b, p. 93).

De acordo com Marx, o mistério da mercadoria, sua aparição fantasmagórica, provém da lógica da equivalência que abstrai dos produtos do trabalho toda a determinidade concreta dos diferentes tipos de atividade produtiva, reduzindo-os à quantidade de força humana aplicada. Como parâmetro de igualação, a quantidade de trabalho, medida pelo tempo socialmente necessário na produção de cada tipo de mercadoria, transforma a atividade humana em trabalho abstrato. O homem que produz já não é mais o fim de sua própria atividade, mas sim o é a mercadoria; tudo é produzido com a finalidade de ser trocado por outra coisa, qualquer que seja a sua utilidade. Os atributos humanos inerentes ao trabalho, 
bem como as suas características sociais, são, pois, encobertos pelo fetichismo da mercadoria. Essa nova forma de sociabilidade, esse novo modo de ser do homem no processo de (re)produção da própria vida, edifica um ethos reificado, coisificado, em que as relações com os outros se tornam meios para a relação tornada essencial, qual seja, a relação entre objetos. Logo, a mercadoria passa a ter o poder de estabelecer as relações sociais, pois, como um ente animado, ela é significada - mentalmente representada - como o sujeito dessas relações.

A partir disso, o caráter social do trabalho se manifesta unicamente por meio da troca e os seus sujeitos propriamente ditos, os homens, alienam-se tanto de suas necessidades quanto de seu potencial criativo e gregário. À medida que vai sendo negada a objetivação de si no produto de sua atividade, com o caráter social de seu trabalho passando a manifestar-se tão somente através da troca, esses homens vão incorporando a alienação como forma de expressão da vida. Assim sendo, no interior da sociabilidade mercantil fetichista, aqueles que trabalham seguem como estranhos à sua peculiar natureza, a despeito de as referidas relações sociais de produção serem continuamente reiteradas pela própria práxis humana,

\section{A ECONOMIA dO CAPITAL E A RADICALIZAÇÃO DA REIFICAÇÃO E DO ESTRANHAMENTO}

Como produto histórico do fetiche da mercadoria, o fetichismo do dinheiro ${ }^{7}$ surge radicalizando ainda mais a antítese da exteriorização do humano nas relações sociais de produção. Ao assumir a forma de equivalente universal por meio do qual todas as mercadorias expressam seu valor, o dinheiro passa a exercer o poder do vínculo, já que, uma vez assumido como uma "espécie de valor de uso-em-geral", [ele] atua "como o mediador imediato de todas as relações" (GUEDES, 2014, p. 139). Desse modo, se sob o fetiche da mercadoria o trabalho se converte em propriedade do objeto produzido, agora ele fica convertido à propriedade de um objeto universal que é o dinheiro. É assim que, com o ocultamento das mediações materiais e subjetivas inerentes à produção de valor, a sociabilidade mercantil vai se constituindo como cada vez mais estranha ao que existe de genuinamente humano no processo de trabalho. Os homens passam a

[proceder] de maneira atomística no processo de produção social e suas relações de produção assumem uma configuração material que não depende de seu controle

\footnotetext{
${ }^{7}$ Em $O$ capital (MARX, 2004b) e, inspirado nele, também em Guedes (2014), há uma minuciosa descrição e análise do processo de conversão da forma-valor em forma-dinheiro. Do mesmo modo, em ambos se encontra o detalhamento do processo de conversão do dinheiro em capital.
}

Sapere aude - Belo Horizonte, v. 9 - n. 18, p. 104-121, jul./Dez. 2018 - ISSN: 2177-6342 
nem de sua ação consciente individual [...]. O enigma do fetiche do dinheiro é [...] nada mais do que o enigma do fetiche da mercadoria em forma patente e deslumbrante. (MARX, 2004b, p. 117).

Esse misticismo negador da autorrealização humana recebe um incremento decisivo com a passagem da forma dinheiro à forma capital como consequência do desenvolvimento da fórmula de circulação da produção. De intermediário da aquisição de mercadorias, o dinheiro converte-se a meio para adquirir mais dinheiro através da compra de uma mercadoria capaz de ser, "ela própria, fonte de valor, ao ser utilizada [...]. Tal mercadoria é [...] a força de trabalho, cujo valor de uso consiste justamente na produção de valor" (GUEDES, 2014, p. 145). O ethos mercantil capitalista configura, assim, o nível mais avançado da inversão fetichista em que a liberdade própria à natureza humana manifesta-se na relação-capital como a oferta, livre ao trabalhador, da sua capacidade produtiva ao possuidor dos meios de produção e de sua subsistência. Nessa lógica invertida, sua liberdade é definida também como o seu total despojamento de qualquer outro meio para a reprodução da própria vida.

Tornada pressuposto da forma capitalista de produção, essa liberdade contraditória leva o homem ao despertencimento de si para pertencer-se ao capital, a algo que lhe é estranho, que o domina e submete a sua consciência e a sua vontade a fins que não lhe pertencem. Nesse sentido, ao ser alienada pelo capital, a capacidade produtiva torna-se, para o trabalhador, apenas o meio para adquirir, pela troca, certo valor representado pelo salário. Por meio da capacidade de produzir, o ser que trabalha se reproduz fisicamente, não para si próprio, mas para o capital. Para esse último, personificado no comprador da força de trabalho, as propriedades humanas que acompanham a capacidade produtiva do trabalhador lhe interessam tão somente enquanto possam ser destinadas a garantir, através da produção de mais-valia, a sobrevivência do capital.

No reino do fetichismo do valor, o salário materializa a relação contratual entre o comprador e o vendedor da força de trabalho, sob o signo da ilusória liberdade. Ele institui o corpo e a alma do trabalhador como novos objetos da propriedade privada do capitalista.

A principal função do tão glorificado “contrato" [é], portanto, a introdução [...] de uma nova forma de "fixidez" que [garante] ao novo senhor o direito de manipular os seres humanos supostamente "livres" como coisas, objetos sem vontade própria, desde que estes [escolham] livremente celebrar o contrato em questão, "alienando voluntariamente aquilo que lhes [pertence]”. (MÉSZÁROS, 2006, p. 38, grifos do autor). 
O contrato de trabalho constitui-se, pois, como a mediação fundamental da relação-capital, consagrando uma forma de vínculo entre o capitalista e o trabalhador, no qual seguem, lado a lado, "o primeiro, com um ar importante, sorriso velhaco e ávido de negócios, [e] o segundo tímido, contrafeito, como alguém que vendeu sua própria pele e apenas espera ser esfolado" (MARX, 2004b, p. 206). Paradoxalmente, o homem que trabalha nessas circunstâncias (re)produz a vida, ao mesmo tempo em que a nega em sua essencialidade. Ele garante quotidianamente sua existência sem poder efetivar a sua verdadeira realidade humana nas relações que estabelece com o seu trabalho, consigo e com o outro.

Deixando o trabalho de ser um resumo do fim posto conscientemente por seu realizador - segundo sua inventividade e sua vontade -, a confrontação entre ambos só pode ser uma relação de exterioridade que se manifesta em estranhamento. Igualmente estranha é a relação desse sujeito com sua atividade, pois,

como poderia o trabalhador defrontar-se alheio (fremd) ao produto da sua atividade se no ato mesmo da produção ele não se estranhasse a si mesmo? O produto é, sim, somente o resumo (resumé) da atividade, da produção. Se, portanto, o produto do trabalho é a exteriorização, então a produção mesma tem de ser a exteriorização ativa, a exteriorização da atividade, a atividade da exteriorização. No estranhamento do objeto do trabalho resume-se somente o estranhamento, a exteriorização na atividade do trabalho mesmo. (MARX, 2004a, p. 82, grifos do autor).

Ao invés de exteriorizar-se no mundo pelo trabalho, o homem cria um mundo exterior e estranho à sua natureza, castrador da sua energia física e espiritual, em um movimento marcado pela personificação das coisas e pela coisificação do seu ser. Porquanto ele estranha-se a si mesmo como ser criativo e livre, só se sentindo como tal quando entregue às funções meramente naturais, mais propriamente na satisfação de suas necessidades corporais. Para ele, a vida não é atividade, nem a atividade é vida; uma é apenas meio para a outra, segundo suas determinidades e não de acordo com o caráter genérico da atividade vital consciente. Daí o trabalhador estranhar também a dimensão genérica da sua existência como ser produtivo. Frente ao outro, ele se sente sozinho e reconhece sua essência como mera individualidade. E sua existência individualizada passa a "[exigir] apenas meios para sua subsistência, mas não formas especificamente humanas - [...], isto é, sociais - de autorrealização, as quais são ao mesmo tempo manifestações adequadas da atividade vital de um Gattungswesen, um ‘ser genérico”” (MÉSZÁROS, 2006, p. 80).

No ethos mercantil capitalista, a radicalidade da atomização do homem que trabalha - atomização essa iniciada com a divisão do trabalho - é apenas um exemplar de que 
os desafios que se apresentam à sua autorrealização se tratam de obstáculos interpostos e ao mesmo tempo autoimpostos nos processos de reprodução da vida. A reiteração da práxis produtiva, pelos trabalhadores, leva-os a assumir uma forma de manifestação da vida totalmente voltada para fora deles, para fora de sua consciência e de sua liberdade e, consequentemente, para fora da universalidade, da generalidade humana.

Nessa práxis invertida, marcada pela objetivação do ser que trabalha sob a forma da alienação e do estranhamento, a realidade por ele criada a ele retorna como algo dotado de uma personalidade superpotente, o capital. Porém, vale sublinhar uma vez mais que essa entidade não se faz sozinha como sujeito dotado de uma objetividade absoluta; ao contrário, o capital é feito e legitimado como tal a partir do modo como os indivíduos exprimem a realidade econômica que eles mesmos reiteram relacional e quotidianamente. A despeito disso, em face de seu caráter autorreflexivo, ou seja, por ter somente a si como finalidade, o capital impõe, no curso das relações sujeito-natureza e sujeito-sujeito, toda a sua força negadora da autoexpressividade humana.

As condições de possibilidade para a exteriorização, para a expressão de si do sujeito no mundo por ele construído socialmente, são tanto mais distanciadas dele quanto mais aprimorada se torna a forma capitalista de produção. Pois, não obstante o ocultamento das articulações entre suas mediações fundamentais - a saber, "dinheiro, meios de produção e força de trabalho, produto-mercadoria, dinheiro novamente" -, as inovações técnicas e tecnológicas dos processos de trabalho ${ }^{8}$ dirigem-se diretamente a elas, ampliando os ganhos do capital e contribuindo para uma desrealização ainda mais dramática do trabalhador (GUEDES, 2014, p. 190).

$\mathrm{Na}$ atualidade, o incremento de tais inovações - a partir de estratégias de gestão da produção admitidas como cada vez menos autoritárias - obscurece ainda mais a dimensão multifacetada da externalidade do trabalho diante de quem o realiza. Voltados para a maximização do aproveitamento da propriedade ativa do trabalhador, a sua força de trabalho, todos os mecanismos historicamente criados para aperfeiçoar a relação-capital e assim reproduzi-la em um crescente de acumulação, agudizam a separação entre o sujeito que trabalha e a sua atividade, que já não é sua. Em termos efetivos, quanto mais o modo

\footnotetext{
${ }^{8}$ A obra Condição pós-moderna de David Harvey (1989) é importante referência para a compreensão das evoluções do capitalismo após o desenvolvimento da maquinaria e da indústria, já abordadas por Marx em "O capital". Harvey desenvolve questões basilares do processo de consolidação da economia do capital que, quanto mais se aprimora, mais potencializa as relações intercoisais, reificantes, contrárias, portanto, à autorrealização humana.
} 
capitalista de (re)produzir a vida se aperfeiçoa, mais robusto se torna o vínculo orgânico existente entre a forma-valor, com todas as suas mediações constitutivas, e o estranhamento como manifestação da alienação. Intensifica-se, por conseguinte, a corrupção do vínculo ineliminável entre o reino da necessidade e o reino da liberdade. Triunfa a subsunção do segundo pelo primeiro, mediada pela busca tão somente da satisfação de carências; carências essas que, na sociabilidade decorrente da mercadoria, não são todas inerentemente humanas.

\section{CONSIDERAÇÕES FINAIS}

No traçado expositivo das mediações que constituem a economia do capital, procurou-se ressaltar a dialeticidade subjacente à relação do caráter ontológico do trabalho com o seu caráter histórico. Diferentemente do que se tende a concluir à primeira vista, apesar das inversões que evoluíram no interior das relações de produção, a centralidade ontológica do trabalho não é negada pela história. Isso porque as próprias determinidades que impossibilitam ao homem realizar-se humanamente pela atividade que realiza já surgem diante de um ser autofundado pelo trabalho. O trabalho como categoria mediadora da descoberta, pelo homem, de sua própria humanidade é condição essencial da qual, exatamente por isso, não se pode retroceder no curso da história. Não se trata, pois, de mais uma mediação entre outras, e sim de uma mediação fundante central, a partir do que a história humana se desdobrou, tomando os rumos da desumanização.

Em face disso, cabe ponderar, por fim, que não sendo a alienação, o estranhamento e a reificação atributos da natureza humana, mas produtos históricos que emergem como modos de expressão da vida, sempre haverá a possibilidade de negá-los como negação da autorrealização humana. Tal perspectiva se afirma como algo indubitável, já que, mesmo vivenciando a situação de alienado, o ser livre e criativo nunca deixa de existir como potencialidade.

A negação da negação ${ }^{9}$ não significa um recuar na história, mas sim a (re)conquista da humanidade do homem através de uma práxis revolucionária capaz de negar o caráter invertido das relações capitalistas de produção e realizar a suprassunção do reino da liberdade sobre o reino da necessidade. Afinal, superar os limites da esfera da necessidade, se

\footnotetext{
${ }^{9}$ Nos "Manuscritos econômico-filosóficos", Marx (2004a) apresenta as mediações constitutivas de uma práxis revolucionária, a partir da qual os homens (re)conquistariam o mundo por eles criados como um mundo expressivo e autorrealizador da consciência e da liberdade, inerentes à natureza humana.
} 
autoexteriorizando no processo de produção - ainda que conservando o reconhecimento de si como ser da natureza - é que o garante a afirmação do sujeito humano pelo seu trabalho.

A negação da "afirmação negativa" do homem que trabalha requer, portanto, que a própria economia capitalista seja apreendida não como um ente autônomo, mas sim na sua essencialidade como atividade humana. Tal princípio dinâmico e ineliminável de toda forma econômica deve ser reconhecido "como a forma mais envolvente" da sociabilidade mercantil capitalista, ainda que ele seja continuamente negado pelas mediações que constituem o ethos em questão (GUEDES, 2014, p. 198).

O pensamento marxiano e também o de seus seguidores se volta exatamente para essa dialeticidade desveladora do ineludível caráter de inacabamento do mundo construído pela atividade do homem, isto é, o seu caráter socio-histórico. E é nesse horizonte sempre aberto que o homem, produtor de sua própria história, pode atualizar suas potencialidades com vistas a instaurar um novo ethos em que o fim de sua ação seja o seu próprio fim como ser efetivamente livre e criativo.

\section{REFERÊNCIAS}

GUEDES, Édil. A economia como sistema de representação em Karl Marx. São Leopoldo: Ed. Unisinos, 2014.

HARVEY, David. Condição pós-moderna: uma pesquisa sobre as origens da mudança cultural. Tradução de Adail Ubirajara Sobral e Maria Stela Gonçalves. São Paulo: Loyola, 1989.

LUKÁCS, György. Ontologia do ser social: os princípios ontológicos fundamentais de Marx. Tradução de Carlos Nelson Coutinho. São Paulo: Livraria Editora Ciências Sociais, 1979.

LUKÁCS, György. História e consciência de classe: estudos sobre a dialética marxista. Tradução de Rodnei Nascimento. São Paulo: Martins Fontes, 2003.

MARX, Karl. Manuscritos econômico-filosóficos. Tradução de Jesus Ranieri. São Paulo: Boitempo, 2004a.

MARX, Karl. O capital: crítica da Economia Política. Livro 1, Volume 1: O processo de produção do capital. Tradução de Reginaldo Sant'Anna. 22.ed. Rio de Janeiro: Civilização Brasileira, 2004b.

MARX, Karl; ENGELS, Friedrich. A ideologia alemã. Tradução de Luís Cláudio de Castro e Costa. São Paulo: Martins Fontes, 1998. 
MÉSZÁROS, István. A teoria da alienação em Marx. Tradução de Isa Tavares. São Paulo: Boitempo, 2006.

MÉSZÁROS, István. Para além do capital: rumo a uma teoria da transição. Tradução de Paulo Cezar Castanheiras e Sérgio Lessa. São Paulo: Boitempo, 2011.

OLIVEIRA, Manfredo Araújo de. Ética e sociabilidade. São Paulo: Loyola, 1993.

SMITH, Adam. A riqueza das nações. Investigação sobre a natureza e suas causas. Tradução de Luiz João Baraúna. São Paulo: Abril Cultural, 1983 (Os Economistas).

VÁZQUEZ, Adolfo Sánchez. Filosofia da práxis. Tradução de Maria Encarnación Moya. Buenos Aires: Conselho Latinoamericano de Ciencias Sociales - CLACSO. São Paulo: Expressão Popular, 2007.

VAZ, Henrique Cláudio de Lima. Marxismo e ontologia. In: Ontologia e história. 2.ed. São Paulo: Edições Loyola, 2012. 